\title{
https://helda.helsinki.fi
}

\section{What is evidence required for and who generates that evidence in the Finnish Educational System?}

\section{Niemi, Hannele}

Springer International Publishing AG 2017

Niemi , H 2017 , What is evidence required for and who generates that evidence in the Finnish Educational System? in M Y Eryaman \& B Schneider (eds), Evidence and Public Good in Educational Policy, Research and Practice . Educational Governance Research , vol. 6 , Springer International Publishing AG , Cham , pp. 43-62 . https://doi.org/10.1007/978-3-319-58850-6_3

http://hdl.handle.net/10138/312067

https://doi.org/10.1007/978-3-319-58850-6_3

unspecified

acceptedVersion

Downloaded from Helda, University of Helsinki institutional repository.

This is an electronic reprint of the original article.

This reprint may differ from the original in pagination and typographic detail.

Please cite the original version. 
In Evidence and Public Good in Educational Policy, Research and Practice.

Eryaman, M. Y. \& Schneider, B. (Eds.). Cham: Springer International Publishing AG, s. 43-62 20 (Educational Governance Research, 6)

\title{
What is evidence required for and who generates that evidence in the Finnish educational system?
}

\begin{abstract}
The article will analyze the major opportunities as well as the difficulties in providing and applying research-and evidence-based knowledge in the Finnish educational system. It asks what purposes evidence is required for and who provides that evidence. The chapter introduces the Finnish enhancement-led evaluation policy and its main principles relating to evidence production. In the Finnish system, evidence is a broad concept covering national and international evaluations, researcher contributions, and the practitioner's capacity to create evidence. In the Finnish educational system, evidence comes from different sources and is also discussed with different partners. Creating evidence is not a unidirectional process. It is a joint process where researchers, policy-makers, and practitioners work together in a complementary fashion. However, there are several challenges. Some difficulties arise from the disconnection between decision-makers at policy level. It is also very demanding to generate evidence for the whole educational ecosystem that has equity and lifelong learning as its main objectives. The third issue to overcome is how to disseminate and communicate evidence to different users.
\end{abstract}

\section{Introduction: Public or common good and evidence in the Finnish context}

Daviet (2016) writes that in global public policy education has commonly been considered a public good. He refers to international organizations, particularly United Nations (UN) agencies and, among these, UNESCO, which have promoted the notion of a public good for decades. A "public good" has traditionally been defined using Samuelson's (1954) notion, whose remarkable criterion is that an individual's consumption of one leads to no subtractions from any other individual's consumption of it. In other classical definitions, such as Musgrave's, public goods are contrasted with private goods and services. Definitions of public good often assume that it is non-competitive and non-excludable, meaning that it is impossible to exclude any individuals from consuming the good (Musgrave, 1969; Desmarais-Tremblay, 2014). All these definitions come from economics and are rooted in neoclassical economic theories.

Recently, critical voices have emerged questioning the relevancy of these definitions in the changing educational landscape (UNESCO, 2015). Daviet (2016) questions how well the economic conception of public good provides a real basis for understanding the social, cultural, and ethical dimensions of education. Daviet (2016, p. 5) warns: "The neoclassical theory, which undergirds the concept of public good in its largest sense, builds on a set of interrelated theoretical assumptions, among which are methodological individualism and utilitarianism. Methodological individualism considers a standard and abstract individual as a unit of analysis." Daviet sees how transforming governance models, the increasing 
involvement of civil society organizations, and the growing trend towards the privatization and commodification of education place the notion of a public good in a new situation. She asks how education can go can "beyond narrow utilitarianism and economism that is integrated with the multiple dimensions of human existence" and calls for a humanistic and holistic approach to the public good of education as an alternative to earlier economically rooted definitions. Her concept of a common good enables comprehension of the changes affecting the educational landscape by considering structures of governance and procurement that involve not only the state, but also a large variety of non-state actors. Finally, the concept of a common good, encompassing ethical and political concerns, provides a principle for rethinking the purpose of education. Daviet $(2016$, p. 8) defines common goods in the following way: "[T]hose [goods] that contribute to the general interest, enabling society as a whole to be reinforced and to function better, as well as individuals to live better. Therefore, common goods must benefit all. Defining what is a common good is a collective decision that involves the state, the market and civil society."

The discussion about public and common goods is very interesting from the viewpoint of the Finnish educational system. Equity in education has been a leading concept of the Finnish educational system since the late 1960s. Finnish basic education has been logically developed according to the comprehensive school model, which guarantees everyone equal opportunities in education irrespective of sex, social status, and ethnicity, among others, as outlined in the Constitution. Basic education is a basic right of citizenship. It is free of charge at the basic level and mainly also at other levels; even in higher educational settings, no tuition fees are charged for students from Finland or other European countries. Education in Finland is a public service, and the equity principle covers all educational levels from early childhood education to higher and adult education. Equity is related to the large societal issues to which education is one contributor; to other services, such as health and social welfare issues. All these contributions have the purpose of creating coherence in society. In educational services, the main point is how well the whole educational ecosystem system supports learning-not narrowly focusing on only cognitive learning outcomes, but paying more attention to the whole system's capacity to produce high quality services (Finnish National Board of Education [FNBE], 2016).

Education in Finland is publicly funded and, in fact, there are only a few private schools in the formal educational system. The private sector is also involved in adult education, and many public-private combinations exist. Even though education provided by public entities such municipals/cities, through the provision of teaching and learning materials, local facilities, and services, many connections to private companies exist. New digital learning environments also cross between the public and private spheres (Niemi, Multisilta, Lipponen, \& Vivitsou, 2014). Finnish education fits within traditional definitions in the sense that it is non-competitive and non-excludable in a wide sense. The main principle is that every school must provide a quality education so that parents need not worry about their children having access to the next level of the educational system. The Finnish system is decentralized, and the local needs of students and learners are seen as important. In this sense, the system comes close to Daviet's 
definition of common good because education may have different shapes and ways of being implemented depending on local conditions and communities. The understanding of a public or common good in Finland means that educational services go beyond pure economics and include the objective, or even norm, of supporting different learners for their future lives. It means common services for all, but also special support for those who have learning difficulties, including in some cases personalized learning routes that are publicly funded. This means that in certain situations public money and resources are allocated to the weakest students based on their learning difficulties. In that sense, a public good is exclusive because its consumption by some leads to subtractions from others' consumption of that good. The equity principle means that there are special support systems for those who would otherwise be in danger of dropping off later in life. We may conclude that education is public service guaranteed by the Constitution. It is publicly funded, but also has many features of a common good because its objectives include wider purposes, not only educational consumption. It aims for personal growth on an individual level, but also competence and skills that matter for the wellbeing of communities and the promotion of social coherence.

This requires that the concept of evidence for police and practice in education be seen from much wider perspectives than only economics or certain universal standards. As Luke, Green, and Kelly (2010) remark, the use of evidence and science to address issues of educational equity and social justice is not straightforward. They emphasize that, when defining evidence, we should see that educational systems are "profoundly troubled by complexity, diversity, and difference." In the Finnish case, the equity principle means that evidence comes not only from one source or actor. In the Finnish case, evidence is related to how the whole system works for equity and provides high quality education for all. In the Finnish discussion, having a value basis is a key issue. Evidence-based policy and practice are related to the values of education in the whole educational system (Laukkanen, 2008; Niemi, 2016; Sahlberg, 2011). In addition to equity, the other important aim is to provide lifelong opportunities for all citizens. These objectives are connected to a decentralized educational administration and a curriculum that allows much freedom at the local level. Teachers' high standards of academic education and their professional roles create conditions that have a strong effect on evidence-based policy and practice. The special feature of evidence-based policy is enhancement-led evaluation, in which the main goal is to collect evidence for improvement, not for rankings.

In this chapter, these frames are considered and analyzed in terms of how they modify the concept of evidence in the Finnish educational system. The article has two questions: (1) What is evidence for, and (2) By whom and with whom is evidence created in the Finnish education system?

\section{What is evidence for in the Finnish context?}

The relationship between research, policy, and practice has been under discussion since 2000 in many academic publications and has also been the focus of policy- 
level discussions in many countries (e.g. Boaz, Ashby, \& Young, 2002; Hammersley, 2004, 2005). Globally, the Organisation for Economic Cooperation and Development (OECD) has been very active in this discussion (Burns \& Schuller, 2007; Schuller, 2006). Medicine is often referred to as a good example of evidencebased policy and practice, particularly its Cochrane system (www.cochrane.org/evidence), which provides the latest knowledge for practitioners and for public use. It is based on research work from the academic community and is transparent. In Finland, a similar open database called Good Care (Käypä hoito) is open to the public, providing information and suggestions for medical care via the Internet. In the international discussion there has been an active debate regarding education: Should a similar kind of database be created for education and is it possible? In this discussion, educational research and its capacity to provide evidence have often been subject to criticism. Tom Schuller (2006) notes and refers also to Angrist (2004) that educational research has been strongly criticized for its weakness in not even attempting to supply rigorous evidence on the effects of education. Some of the criticism concerns the low academic standing of educational research, and the low level of impact on policy or practice.

The OECD, CERI, and the EU Commission have repeatedly required more policy relevance and an interdisciplinary approach (e.g. Benavot et al., 2005; Greco et al., 2005). Boaz, Ashby, and Young (2002, p. 7) summarize the current deficiencies regarding why educational research is not serving policy or practice:

Much research is considered less than robust, there are paradigm wars, eclectic methods competing rather than complementing, large datasets are analysed but there is relatively little true experimentation, fragmented research community, no accessible database of research evidence (but fresh initiatives underway), few systematic reviews.

Some educational researchers have proposed very experimental and controlled models for educational research in order to produce more cumulative knowledge (e.g. Slavin, 2002). These suggestions have raised very controversial opinions among education researchers.

Berliner (2002) and McCormick (2003) also remark that educational research is the hardest science of all when striving for research and evidence-based policy and practice because of the enormous complexity of educational phenomena. Berliner writes:

Our science forces us to deal with particular problems, where local knowledge is needed. Therefore, ethnographic research is crucial, as are case studies, survey research, time series, doing experiments, action research, and other means to collect reliable evidence for engaging in unfettered argument about educational issues. A single method is not what the government should be promoting for educational researchers. It would do better by promoting argument, discourse and discussion. (Berliner, 2002, p. 20) 
Complexity, the situational nature of education, as well as the practitioner's role are issues that make the concept of evidence very challenging in education.

Equity has been a leading principle of Finnish educational policy since the late 1960s. Equity means equal opportunities for everyone to continue their learning and education at any phase in their lives. This principle entails that everyone has sufficient learning skills and opportunities to educate and develop themselves in different learning environments (Ministry of Education and Culture [MEC]). The MEC summarizes the official educational policy thus: "The welfare of Finnish society is built on education, culture and knowledge. The flexible education system and basic educational security make for equity and consistency in results" (MEC, 2016a). Flexible system and structures mean that students always have the opportunity to continue their education, even when they have failed at some point along their learning path.

In this kind of system, the required evidence must reveal how the system works. The Finnish educational system has been referred to as an ecosystem, where the different levels and sectors should function as a whole when aiming at high quality learning for all (Niemi et al., 2014; FNBE, 2016).

The landscape of education and teaching is under extreme pressure in Finland, as it is everywhere. This changing environment impacts the concepts of learning, teaching, and knowledge, with new technology and rapid changes in the economy, societal structures, industrial life, and vocations requiring changes in schools and teaching. How does this Finnish system provide good education for people from different backgrounds and in its various different learning environments?

In Finland, the required evidence should be comprehensive, covering the whole system and still giving detailed information regarding the different levels of education. This is an aim and a challenge. In the international debate on evidence, research reviews and meta-analyses are often focused on a narrow theme or phenomenon. In the Finnish case, evidence does not come from any once source.

\subsection{The national enhancement-led evaluation policy}

A quest for good learning outcomes is on the educational agenda of many countries. Globally, much controversy exists over what is the best way to use assessment as a tool through which to achieve high learning outcomes. Some countries have chosen standardized testing, which stresses competition between schools, and focuses on measurable performances. The Finnish choice has been enhancement-led evaluation at all levels of education (Kumpulainen \& Lankinen, 2016). The assessment of outcomes is regarded as an important tool through which to improve education. There is no standardized testing, nor inspection system to control the educational arrangements at schools or institutions. Instead of inspection, there is an evaluation system (FNBE, 2016).

At a national level, the main actor is the Finnish Education Evaluation Centre [FINEEC], (2016). It is an independent government agency responsible for the 
evaluation of education. It carries out evaluations related to education including the operations of education providers from early childhood education to higher education. The key operating principles of FINEEC are the independence of evaluation and enhancement-led evaluation. Independence refers to the freedom of evaluation methods, the organization, and results from the influence of, for example, the MEC or other parties. The concept of enhancement-led evaluation means that the purpose of all evaluations is linked to improvements in the educational system. It has many similar features to the concept of communicative evaluation (Niemi \& Kemmis, 2012) that defines evaluation with three functions.

As a process, communicative evaluation (Niemi, 1996) sets out to interrupt our usual ways of thinking and doing things with the explicit intention of creating shared frameworks of understanding about (a) where we are now (revelation), (b) where we are heading (anticipation), and (c) how we can and should move forward together (building communication and partnerships). Practically speaking, we see communicative evaluation as characterized in terms of three functions (Niemi \& Kemmis, 2012, p. 64):

- Revelation: helping people to understand cultural, social and interpersonal dynamics in and around programmes and settings, and to do so in a critical way;

- Anticipation: helping people to orientate towards the future in increasingly unsettled times; and

- Building communication and partnership: helping people to work together for transformation, not only at local levels but also in relation to global issues, trends and tendencies.

FINEEC (2016) expresses its principles as follows:

Enhancement-led evaluation emphasizes participation, as well as trust between the party implementing the evaluation and evaluation participant, and the responsibility of education providers and higher education institutions in the development of the quality of their operations. In enhancement-led evaluation, the methods will be tailored according to the objectives of the evaluation and theme to be evaluated.

In its strategy, FINEEC (2016) has defined four interrelated focus areas:

1. Developing learning and competence with evaluation. Evaluations implemented with different enhancement-led methods aim at improving learning results and competence at all educational levels.

2. Evaluation activities that cover all educational levels provide information on the functionality of the entire educational system and policy. The evidence-based evaluation information forms a basis for development work. Evaluations are also targeted at the educational level boundaries and various transition phases. 
3. Evaluations are targeted at societally important and critical themes. Based on an analysis of the changes in the operating environment, significant development targets in education which are not included in the Evaluation Plan, may be raised for evaluation.

4. FINEEC supports education providers and higher education institutions in developing quality management by evaluating their quality systems and producing information on good practices in quality management and development, as well as by spreading the information across different educational levels. Moreover, FINEEC supports schools, educational institutions and higher education institutions in utilizing national evaluations and self-evaluations as well as in strengthening the enhancement-led evaluation approach.

Since the mid-1990s, the Finnish National Board of Education has conducted national assessments of learning outcomes, mostly in the 9th grade of basic education. Regular assessments have been carried out in mathematics, the student's mother tongue (either Finnish or Swedish), and literature, and occasionally in other subjects as well. This task was transferred to FINEEC in 2014. These assessments have been and will be sample-based and usually cover 10$15 \%$ of the age cohort. The assessments are based on the objectives of basic education. The items and contents of the assessments are pre-tested with schools outside the sample and are designed based on teacher feedback. The assessment results are reported as summaries, not for individual schools, for the MEC, the Finnish National Board of Education, teacher education institutes, and educational providers, as well as for schools and teachers. All schools in an assessment sample receive an individual feedback report. Evaluations also consist of questions on the teaching and assessment methods in participating schools, educational resources, and on student motivation, their self-concept as learners, and on how they view the usefulness of the subject matter.

\subsection{The role of international evaluations in the Finnish context}

Finland has been part of several international evaluations (e.g. the Programme for International Student Assessment [PISA]; the Trends in International Mathematics and Science Study [TIMSS]; the Progress in International Reading Literacy Study [PIRLS]; the Teaching and Learning International Survey [TALIS]; and PIAC). The Finnish system has also received much attention because of its 15year-old students' high learning outcomes in the international PISA measurements. Many researchers, such as Gert Biesta $(2009$, p.1), note that in recent years, international measurements of student learning outcomes have become important sources for educational planning:

One of these tendencies is the rise of an international 'league-table industry' which is increasingly influencing education policy at national and local level. Studies such as the Trends in International Mathematics and Science Study (TIMSS), the Progress in 
International Reading Literacy Study (PIRLS) and, most notoriously, OECD's Programme for International Student Assessment (PISA), generate a never-ending stream of comparative data that are supposed to tell us which educational systems are better and which are best.

However, in the Finnish case, evidence consists of much more than PISA scores. Finnish policy-makers see that the additional value of international measurements to Finland is linked to broad knowledge production and to peer viewpoints in the countries outside of the EU. These international measurements provide an opportunity to compare Finland's situation to other countries; evidence that is interesting in terms of the aims and policies of the Finnish educational system (Laukkanen \& Palonen, 2011). The results from the international measurements are used to identify how to improve the system. Even though Finland is still among the best educational countries in the world, many Finnish analyses of the PISA results and trends focus particularly on the weaknesses and concerns highlighted in those results. This approach is useful for finding out what the most important issues are for improving Finnish education. OECD data are used in further analyses for national purposes, as Välijärvi and Sulkunen (2016, p. 1) write:

The decreasing trend in average performance and the increasing number of low performers have gained wide attention in the educational field in Finland, and rightly so. Moreover, it is evident that educational equality and equity which have been-and still are-in the heart of educational policy in Finland shows disconcerting development as the gender gap is widening and the impact of home background on students' reading literacy performance has increased. Particularly students from culturally disadvantaged homes are at risk and show relatively steep decrease in both reading engagement and performance. These trends show that the Finnish school has difficulties in supporting students' growth and development of key competencies in the changed context, where technologies related to literacy, textual landscapes and literacy practices are changing constantly.

Based on the recent PISA results, the researchers (Välijärvi \& Sulkunen, 2016) claim that the Finnish educational system needs to find new pedagogical ways to promote the development of students' reading and mathematical literacy (including digital literacy), and also to support the growing number of lowperforming students who do not necessarily receive adequate support from home. These challenges have already been recognized in the earlier analysis requested by the MEC: "Measures will be taken to reduce inheritance of education and to minimise gender differences in learning outcomes, participation in education and in the completion of studies" (MEC, 2012).

The recent PISA results and the other assessments have led to several further measures and national programs being launched to buck the negative trend and to update Finnish education to meet with 21st-century demands. Some are 
substantial reforms, such as the Finnish National Core Curriculum for Basic Education that was recently revised following the usual 10-year cycle, but also taking into account the results from national and international evaluations. The reform process was very interactive, involving teachers, researchers, teacher educators, and a wide range of different societal stakeholders, parents, teacher unions, and labor markets (Vahtivuori et al., 2014). The curriculum emphasizes a new pedagogical culture in which students will have ownership of and an active role in their learning. In addition, the Finnish MEC launched subject-specific national development programs, e.g. the Joy of Reading (Lukuinto), to strengthen the literacy skills of 6-16-year-olds and increase their reading engagement, with the special target of boys, who are overrepresented among the low performers. Another program targets mathematics and science learning for 6-16-year-old students and their teachers (MEC, 2016b). A common aim, according to the MEC and FNBE, is to develop a new pedagogical culture to support, on the one hand, collaborative learning, and, on the other hand, individual learning.

\subsection{Research providing evidence}

National evaluations use scientific methods for data gathering and analysis. They inform policy-makers, practitioners, and other stakeholders with research-based knowledge. In addition, several other research provisions come from universities. The following research bodies are located within universities:

\section{The Finnish Institute for Educational Research (FIER)}

(https://ktl.jyu.fi/en ) is a multidisciplinary centre for educational research, assessment, and development, based at the University of Jyväskylä, Finland. Its research covers the entire educational system, from pre-school to higher education, and the links between vocational and academic education and working life. Co-operation with schools, educational administrators, workplaces, policymakers, and the media is a key element in its operational strategy, which aims at increasing the effectiveness of research findings. The FIER collaborates extensively with the OECD, various EU Agencies and IEA publications.

\section{[The] Centre for Educational Assessment}

(http://www.helsinki.fi/cea/eng/ ) at the University of Helsinki focuses on students' competences in the curricular subjects to fostering their aptitude for learning later in life. The important theme is learning to learn as the foundation for lifelong learning. The Centre works in collaboration with schools and municipalities in the fields of educational assessment, research and development. The results of assessment are utilized for monitoring and further developing education in classrooms and at school and municipal level. Assessments implemented at different grade levels or at regular intervals offer the providers of education means to monitor educational effectiveness at municipal and national level.

\section{Research Unit for the Sociology of Education (RUSE)}


(http://ruse.utu.fi/home/) at the University of Turku is a research institute in the field of the sociology of education. Its mission is to produce international high quality research on the social sciences, especially on higher education, education policy, and on the relations between education and the labor market. It also develops methodological solutions for social sciences and modes of analysis for evaluating research and teaching.

In addition, eight universities have a Faculty of Education with teacher education (TE) programs. TE has committed itself to a strong research-based orientation and researchers provide research that is funded mostly by the main national research funders, the Academy of Finland and the National Agency for Technology and Innovations in Finland. The latter has supported the development of educational technology in Finnish schools in recent years with projects in which teachers, students, parents, researchers, policy-makers, and companies work together with joint aims (Niemi et al., 2014).

\subsection{Who should provide the evidence?}

The recent Finnish educational system's roots go back to the late 1960s when a comprehensive school model for all children was established. The ideology of equity and principles of lifelong learning have been the driving forces throughout the educational system. A strong principle of lifelong learning linked with equity has changed the teacher's role and TE radically. Finnish teachers are expected to work with mixed ability groups and to take care of different learners.

Basic education consisting of 9 years of comprehensive school, upper secondary education, and vocational education are financed by the state and local authorities. These educational services are provided by local authorities, which are municipalities or consortiums of municipalities. Municipalities (local authorities) and their schools write their own curricula on the basis of the national core curriculum. Local needs can be taken into consideration in these curricula. Schools can have their own profiles such as e.g., science or music education.

The national core curriculum has an important role in the Finnish system of school development as a means for enabling and managing educational change and also in terms of providing freedom to local actors for making education relevant in local contexts. The current curriculum system in Finland is based on three essential ideas (Vitikka et a., 2016):

- Management by goals given in legislation and in the national core curriculum.

- Autonomy of municipal authorities in providing and organizing education: the local curriculum as a steering document at local level.

- Utilization of teachers as valued experts who develop the schoolbased curriculum as a source for different approaches to schoolwork. 
In the educational literature, there has been much discussion on what the real core and nature of the teaching profession is (Brandsford, Darling-Hammond, \& LePage, 2005; Darling-Hammond, 2010a, 2010b; Hargreves, 2003). Is it an autonomous expert profession or is it more of a craft that does not have a very independent status? In many countries, teachers also face high pressure with high-stake national testing having heavy consequences on teaching and learning in classrooms and narrowing professional autonomy. The Finnish national system provides teachers with the freedom to take into account students' needs and local conditions. It also requires a high ethical commitment from teachers to develop their teaching in such a way that all students can make progress in their learning. Assessments are mainly used to help students to learn better.

When discussing the nature of evidence in the international discussion, many voices stress the role of practitioners in assessing the relevance of evidence. When practitioners are informed through evidence, regardless of its origin (research or e.g. observations), they have the right and the obligation to assess its relevance. In the Finnish educational system, teachers are expected to be autonomous, pedagogically thinking, and critically oriented professionals who take care of different learners. Teachers and principals are both responsible for the quality of education and they also need to acquire evidence that is required for school development. The teacher's role is to translate the equity principle and LLL objectives into practice. In that work, they have much professional freedom, e.g. what teaching and learning material they use, what teaching methods they apply, and how they use assessments to promote student learning.

The Finnish system supports arguments that evidence does not only develop from systematic research. It can also develop from observations and the experiences of experts, policy-makers, and practitioners in their own fields (e.g. Issitt \& Spence, 2005). Hammersley (2004) argues that this evidence does not necessarily emerge from systematic investigations, but it still can be important, and perhaps even more important. There are also many voices that stress the role of practitioners in assessing the relevance of evidence. When practitioners are informed through evidence they have the right and the obligation to assess its relevance. Robertson and Dale (2007) note that users must judge what works when applying evidence in practice. There is always a specific context and they have to ask about not only what works, but for whom, under what circumstances, and so on. How to use research or evidence-based knowledge thus depends upon a mix of evidence and judgement, and this is a dynamic process, in which the teacher or policy-maker is also attuned to the effects and consequences, and uses this knowledge to loop back into the process. Policy-makers and practitioners need the capacity to understand how evidence is built up and how they are part of its construction. If teachers are expected to work as professionals who have freedom and autonomy to make decisions in changing contexts, then they must evaluate what works and what does not.

Some years ago, the European Commission prepared a staff working paper (Commission of the European Communities, 2007; Niemi, 2014) to promote evidence-based policy and practice in education. It invited a small working group 
to the table, whose task was to determine how to create, deliver, and apply evidence-based knowledge in and for education. Hannele Niemi, as a member of the group, developed a model on the basic conditions that are needed in educational policy-making and in the teaching profession to apply evidence in policy and practice. The model was introduced in the European Commission's staff working paper (Commission, 2007; Niemi, 2014). The important message is that no information source or action in itself can promote evidence-based action. If we want teachers to work as high-level professionals, they need certain basic conditions to be met for knowledge creation and agency in their work. The successful application of evidence and research-based knowledge depends on many factors, which are in mutual interaction. The following model (Figure 1) summarizes the main components.

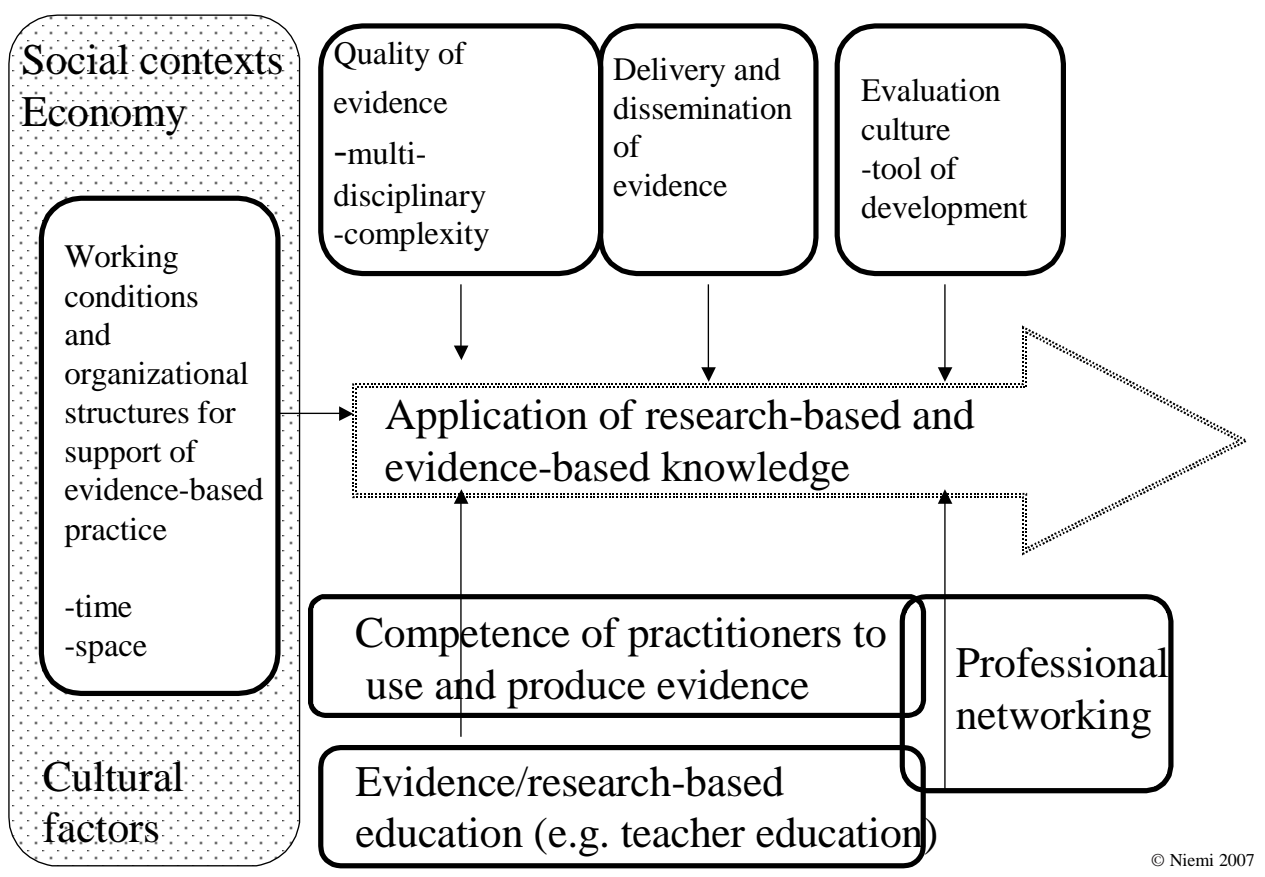

Figure 1. Evidence related to practitioners' work.

\section{Practitioners' role in using and creating evidence}

The above model illustrates that no source of information in itself can promote evidence-based action. Policy-makers and practitioners need the capacity to understand how evidence is built. The more their decisions have a significant impact, the more they need critical scientific literacy to help them understand the validity and relevance of information from research and other evidence sources. Evidence should not only be used but also created by practitioners through reflection and the sharing of experiences. They need open and analytical minds to produce sound evidence and working communities that support practitioners' 
knowledge creation. Educational contexts and decisions are always very complex phenomena, and for this reason, the evidence-based approach must also include multidisciplinary and multi-professional perspectives.

The model also illustrates that knowledge application depends on the social, economic, and cultural determinants of each country, and its regional or local context. It illustrates that all factors influence the different phases of knowledge application. Social, economic, and cultural contexts are in a state of continuous change. Knowledge application in education is not a process of static implementation, but rather a continuous process. Teachers' pre-service education plays an important role in constructing teachers' professional identity and developing their capacity to use different evidence sources. It is an important precondition, but without opportunities to work in their work as decision-makers, creating and using evidence in schools loses its power. Teachers need professional networking, tools for gaining easy access to different evidence sources, and an evaluation culture in which they can use different methods for assessing students' learning and the effectiveness of their teaching.

To educate professionals who have the capacity to use evidence, Finnish TE for both primary and secondary schools involves 5-year programs (consisting of both BA and MA degrees), with high entrance criteria; thus, TE students are very talented and committed to the teaching profession. The aim is that teachers can internalize a research-oriented attitude toward their work. This means that teachers take an analytical and open-minded approach to their work, that they draw conclusions based on their observations and experiences, and that they develop teaching and learning environments in a systematic way. Finnish TE also has a strong research component with the aim of educating teachers to be critical knowledge creators. BA and MA degrees consist of research methodological studies and a thesis, which involves scientific studies. Students learn to read educational research reports, to acquire data, to analyze it, and draw conclusions. Research methods may vary from historical analysis to surveys and experiments. The main objective of these studies is not the completion of the master's thesis itself, but actually to further the process by which students come to see themselves as active studying and working agents. For this aspect of the degree program, the processes of active working and thinking are integrated in various complex and sometimes unexpected ways. The aim of the guiding process is to help students discover and tap into their own intellectual resources and to make them better able to utilize the resources of the study group in which they work (Niemi \& JakkuSihvonen, 2006, p. 37). An important aim of research-oriented studies is also to educate teachers who are able to study and develop their own research-based practices. The critical scientific literacy of teachers and their ability to use research methods are considered crucial. Accordingly, most of Finland's TE programs require studies of both the qualitative and quantitative research traditions.

There are studies that have analyzed teachers and student teachers' concepts and feedback on the TE research studies. Jyrhämä and Maaranen (2016, p. 104) conclude: 
Based on our results, it seems that teachers' inquiry-orientation is first and foremost an attitude towards one's work. The focus is on the development of one's self, as well as the development of the school community, alternative ways of working, reflection, dialogic, feedback etc.

Niemi and Nevgi (2014) has found very much the same kinds of experiences among student teachers. The value of research studies is focused on the following qualities:

- Critical thinking;

- Independent thinking;

- Inquiring and scientific literacy; and

- Questioning phenomena and knowledge.

The general picture is very positive. The student teachers view research studies as valuable for their teaching profession and see them as continuous developmental tasks for their future work. The pre-service TE system has been created to make teachers researchers in their work. We have evidence from research results and TALIS reviews that teachers' in-service training requires many improvements. It is not systematic, and is not based on Finnish teacher's research capacity. The change in direction toward more school-based developmental projects has been very slow. The main reasons for this are the funding system and the fact that pre-service training is provided by universities, and the arrangements for in-service training are the employers' (municipalities) responsibility. Evidence of needs to change teachers' in-service training exists but is not used for a change. Another case concerns ample evidence that in pre-service TE, student teachers need more experience gained from collaboration within school communities, as well as with partners outside the school, especially with parents. However, although we are consistently presented with the same evidence, it seems that some elements of TE culture are very difficult to change.

\section{Discussion}

We can see that in the Finnish educational system there are many channels that provide research-based knowledge for policy and practice. Evidence is available and its meaning is discussed and reflected on in many forums. Most research and evaluation studies are conducted using multiple and mixed methods. Biesta (2007) argues that the current climate, in which governments and policy-makers seem to demand that educational research plays only a technical role, is dangerous. It is a threat to democracy itself. He claims that there is a real need to widen the scope of our thinking about the relation between research, policy, and practice, so as to make sure that the discussion is no longer restricted to finding the most effective ways to achieve certain ends, but also addresses questions about the desirability of the ends in themselves (Biesta, 2007, p. 18).

In the Finnish system, there is a culture of discussion and interaction between research, policy, and practice. However, many challenges still need to be faced. 
Many of them are related to decision making at the political level:

Policy-level disconnectedness. The problem is how to get information to the policy level and step outside the territory traditionally held by policy-makers. The educational ecosystem covers the whole life course. Most lifelong learning issues that are related to the public educational system are under the remit of the MEC, but lifelong learning and equity in education require much more collaboration. Learning in work life is becoming increasingly important. These issues are dealt with the Ministry of the Employment and the Economy. Refugees and immigrants are an increasing population in Finland, and their issues are handled in the Ministry of the Interior. The ageing population is also on the rise in Finland. Health issues are the domain of the Ministry of Social Affairs and Health, but ageing is also very much related to the capacity to learn as lifelong learners and to keep opportunities open to contribute to working life.

Evidence for the whole educational system. In medicine, research can be focused on individual diseases and sometimes on a very narrow symptom. The holistic view of the human body is often missing. This often causes serious problems for patients, even though a particular pain or illness can be cured. In education, the whole educational ecosystem and the interconnecting formal and non-formal environments for lifelong learning set very demanding objectives. Even though the structure of the Finnish educational system is very flexible, transitions from basic education to secondary level, and then through to the tertiary level, consist of many dysfunctions that cause discontinuity in people's learning paths, and additional costs to society via exclusion, drop-out rates, and unemployment. Constantly changing circumstances in the labor market and in terms of societal structures mean that new evidence is constantly required.

Disseminating and communication. In democratic societies, there are many partners and stakeholders who need knowledge about education and who need to be made aware of the latest research and evidence. These kinds of groups are e.g. parents, partners in working life, and companies. The media forms a substantial group of actors as well as holding a large audience. How the different partners understand the quality of evidence and its complexity can vary considerably. There have been cases where the media has taken only one aspect of the evidence and created a totally different message than the one presented in the original assessment or data. We may ask whose responsibility it is to interpret the evidence and to tell the public about it. When evidence is complex and multilayered, considerable communication between the different partners in education is needed.

Evidence is a continuous process. Teachers and policy-makers need high-level analytical skills and a sound understanding of the demands of democracy. They must find, observe, and understand the complexity of educational processes, and examine the evidence from different sources. They also need to be open to acquiring and assessing local evidence. Technical and instrumental knowledge of evaluations and as well as professional culture and traditions may narrow perspectives of needs to change practices (e.g. Carr \& Kemmis, 1986). Scardamalia and Bereiter $(2000,2002,2003)$ have examined the behavior of experts. The 
feature that really distinguishes experts from others is their approach to new problems. The pattern recognition and learned procedures that lead to intuitive problem solving are only the beginning. The expert invests it in what Bereiter and Scardamalia call "progressive problem solving," that is, tackling problems. That increases expertise rather than reducing problems to previously learned routines. In addition to enquiry skills and being open to different kinds of evidence, they need cultural awareness and an understanding of how democracy, research, and evidence-based policy and practice are interrelated.

Evidence-based policy and practice demand cooperation. The Finnish National Board of Education expresses its mission as follows (FBNE, 2016):

There is a wide-spread consensus of the main pillars of education policy and the policy is characterized by cooperation and continuity-evolution rather than revolution. Tripartite partnership among Government, trade unions and employer organisations is an integrated part of policy-making. Participation and consultation of a wide range of different stakeholders play a central role in educational reform. Teachers and the Trade Union of Education as their representative are the key players in the development of education. The main objectives and broad lines of the policy are defined at central level, but the implementation of these is the responsibility of the local level.

The recent understanding of knowledge production has revealed that knowledge is a more comprehensive concept than research or evidence. Knowledge is constructed through research (with its different modes), evidence, literature, and learning experiences. Knowledge creation needs different information sources and social interaction. When promoting evidence-based policy and practice, it is necessary to understand that policy-makers and practitioners are learners in their own work and they create knowledge in their practice. The latest research on learning considers learning as an active individual process, but increasingly we have evidence that it is also a process which is based on sharing and participation with different partners in a community (Nonaka \& Toyama 2003; Scardamalia \& Bereiter, 2003;). If we view knowledge creation as an interactive process, creating evidence and using evidence-based knowledge is no longer a unidirectional process. It is a joint process where researchers, policy-makers, and practitioners work together in a complementary way, seeking evidence for better policy and practice. In this process, networking between the different partners is necessary for the educational ecosystem to thrive.

New sources of evidence create new requirements for managing evidence. In science learning, the concept and method for learning analytics is growing. New technology creates big data and the learner's pathway through the electronic system can be followed and can also connect to other data via traces left in the system. In healthcare and medicine, this approach has been possible and is in use to a higher extent. The patient as well as the doctor can follow this data. This creates new questions: what is one's own data, what kinds of data sets can be connected, who can use "my data," or how I can use my data? Students can already 
retrieve continuous information about their learning processes, e.g. in learning games. This data can also be connected to various brain functions. In the future, the sources and channels of evidence will increase; thus, evidence is not a static concept. It is dynamic and changes along with new methods.

\section{Conclusion}

The landscape of education and teaching is under significant pressure. This changing environment impacts the concepts of learning, teaching, and knowledge, with new technology and rapid changes in the economy, societal structures, industrial life, and vocations requiring changes in schools and teaching. Biesta (2009), Mathinson (2009), and Day and Johansson (2008) argue that the question of good education cannot be solved merely by considering instrumental aims nor resolved without engaging in discussions about values and purposes. The values and purposes of education also have a deep impact on the teaching profession (Campbell, 2008). In the Finnish case connections between equity in education and evidence for improvements in the whole system goes towards understanding what is a common good for the whole society.

Evidence-based policy and practice are a continuous process in which different sources are needed. A particular data source does not have any objective value because the question what for is fundamental. The quality of the evidence must be based on transparent criteria, and part of these is values. Evidence-based policy and practice also needs a continuous discussion between different partners to overcome gaps that cause serious dysfunctions in the educational ecosystem.

\section{References}

Angrist, J.D. (2004). American education research changes tack. Oxford Review of Economic Policy, 20 (2), 198-212.

Benavot, A., Erbes-Seguin, S., \& Gross, S. (2005). Interdisciplinary in EU-funded social science projects. In M. Kuhn \&. S.O. Remoe (Eds.), Building the European research area. Socio-economic research in practice (pp. 115-175). New York: Peter Lang, 115-175

Berliner, D. (2002). Educational research: The hardest science of all. Educational Researcher, 31 (8), 18-20.

Biesta, G. (2007). Why "What Works" Won't Work: Evidence-Based Practice and the Democratic Deficit in Educational Research. Educational Theory, 57, 1-22.

Biesta, G. (2009). Good education: what it is and why we need it. Inaugural lecture. The Stirling Institute of Education. 4th March 2009.

http://www.ioe.stir.ac.uk/documents/GOODEDUCATION-WHATITISANDWHYWENEEDITInauguralLectureProfGertBiesta.pdf

Brandsford, J., Darling-Hammond, L., \& LePage, P. (2005). Introduction in L. 
Darling-Hammond, L., \& J. Brandsford, J. (Eds.), Preparing teachers for a changing world: What teachers should learn and be able to do (pp. 1-40). San Francisco: John Wiley.

Burns, T. \& Schuller, T. (2007). The Evidence Agenda. In T. Burns (Ed.), Evidence in education: linking research and policy (pp. 15-31). Paris: OECD.

Campbell, E. (2008). Preparing ethical professionals as a challenge for teacher education. In K. Tirri (Ed.), Educating moral sensibilities in urban schools (pp. 318). Rotterdam: Sense Publishers.

Commission of the European Communities (2007). Towards more knowledgebases policy and practice in education and training. Commission staff working document. SEC (2007) 1098. Brussels.

http://ec.europa.eu/dgs/education culture/publ/pdf/educ2010/sec1098 en.pd f.

Darling-Hammond, L. (2010a). New Policies for $21^{\text {st }}$ century demands. Interviewed by James Bellanca. In J. Bellanca \& R. Brandt (Eds.), Rethinking how students learn (pp. 33-50). Bloomington: Solution Tress Press.

Darling-Hammond. L. (2010b). Teaching and educational transformation. In M. Fullan, A. Hargreaves, A. Lieberman, \& Hopkins, D. (Eds.), Second International Handbook of Educational Change, (pp. 505-522). New York: Springer.

Daviet, B. (2016). Revisiting the Principle of Education as a Public Good. Education Research and Foresight Series, No. 17. Paris: UNESCO. http://www.unesco.org/new/en/education/themes/leading-theinternationalagenda/rethinking-education/erf-papers/

Day, C. \& Johansson, O. (2008). Leadrship with a difference in schools serving disadvantaged communities: arenas for success. In K. Tirri, K. (Ed.), Educating moral sensibilities in urban schools, (pp. 19-34), Rotterdam: Sense Publishers.

Demarais-Tremblay, M. (2014). On the Definition of Public Goods. Assessing Richard A. Musgrave's contribution. Documents de travail du Centre d'Economie de la Sorbonne 2014.04.

FINEEC (The Finnish Education Evaluation Centre) (2016). https://karvi.fi/en/fineec/

FNBE (Finnish National Board of Education). (2016). Education system.

Education Policy; Quality Assurance National Reference Point. http://www.oph.fi/english/education system education policy http://www.oph.fi/english/education development/quality assurance and eval uation 
Greco, L., Landri, P., Tomassini, M., \& Wickham, J. (2005). The development of policy relevance in European social research. In M. Kuhn, \& S.O. Remoe (Eds.), Building the European research area. Socio-economic research in practice, (pp. 177-237). New York: Peter Lang.

Hammersley, M. (2004). Some questions about evidence-based practice in education. In G. Thomas \& R. Prong (Eds.) Evidence Based Practice in Education (pp. 133-149) ). Maidenhead: OUP/McGraw-Hill.

Hammersley, M. (2005). Is the evidence-based practice movement doing more good than harm?: Reflections on Ian Chalmers' case for research-based policy making and practice, Evidence \& Policy, 1 (1), 85-100.

Hargreaves, A. (2003). Teaching in the knowledge society. Education in the age of insecurity. New York: Teachers College Press.

Issitt, M., \& Spence, J. (2005). Practitioner Knowledge and Evidence-Based Research, Policy and Practice. Youth \& Policy, 88, 63-82.

Jyrhämä. R. \& Maaranen, K (2016). Research orientation in teachers' work. In H. Niemi, A. Toom, \& A. Kallioniemi (Eds.), Miracle of education: The principles and practices of teaching and learning in Finnish schools (Second revised edition) (pp. 91-108). Rotterdam: Sense Publishers.

Kumpulainen, K., \& Lankinen, T. (2016). Striving for educational equity and excellence: Evaluation and assessment in Finnish basic education. In H. Niemi, A. Toom, \& A. Kallioniemi (Eds.), Miracle of Education. The Principles and Practices of Teaching and Learning in Finnish Schools. (Second revised edition). Rotterdam: Sense Publishers (pp. 71 -82). Rotterdam: Sense Publishers.

Laukkanen, R. (2008). Finnish strategy for high-level education for all. In N. C. Sognel \& P. Jaccard (Eds.), Governance and performance of education systems (pp. 305-324). Dordrect, NL: Springer.

Laukkanen, R \& Palonen, M. (2011). OECD:n koulutuspolitiikka Suomen kannalta. Teoksessa R. Laukkanen (Toim.) Tiedosta käytännöksi - OECD tietoon perustuvan koulutuspolitiikan tukena. [ In R. Laukkanen (Ed.) From knowledge to practice. OECD as support for knowledge-based educational policy]. Reports and reviews 2011:20 (pp. 5-13). Helsinki: Finnish National Board of Education,

Luke, A., Green, J., \& Kelly, G. (2010). What counts as evidence and equity? In A. Luke, J. Green, \& G. Kelly (Eds.), Review of Research in Education: Volume 34 (What counts as evidence in educational settings? Rethinking equity, diversity, and reform in the 21st century) (pp. vii-xvii). Washington: American Educational Research Association

Mathison, S. (2009). Serving the public interest through educational evaluation: Salvaging democracy by rejecting neoliberalism. In K.E. Ryan \& J. B. Cousins 
(Eds.), The SAGE international handbook of Educational evaluation (pp. 525-548). Thousand Oaks, CA: Sage.

McCormick, R. (2003). Reliable Evidence for Policy Making in Complex Settings, paper presented to the EMINENT IV Conference, Geneva, 9-10 October 2003.

MEC (Ministry of Education and Culture). (2016a). Education System in Finland. http://www.minedu.fi/OPM/Koulutus/koulutusjaerjestelmae/?lang=en

MEC (Ministry of Education and Culture). (2016b). Key projects reform Finnish education.

http://www.minedu.fi/OPM/Julkaisut/2016/Key projects reform Finnish educ ation.html?lang=en\&extra locale $=$ en

MEC (Ministry of Education and Culture). (2012). Education and research 20112016. A development plan. Department for Education and Science Policy. Helsinki: Ministry of Education and Culture.

Musgrave, R. A. (1969). Provision for Social Goods. In J. Margolis, \& H. Guitton (Eds.), Public Economics: An Analysis of Public Production and Consumption and their Relations to the Private Sectors. London: Macmillan.

Nichols, S.L. \& C. Berliner, D.C. (2007). Collateral Damage: How High-Stakes Testing Corrupts America's Schools. Cambridge, MA: Harvard Education Press.

Niemi, H., Multisilta, J., Lipponen, L., \& Vivitsou, V. (Eds.) (2014). Finnish Innovations and Technologies in Schools. Towards New Ecosystems of Learning, Rotterdam: Sense Publishers.

Niemi, H. (1996). Effectiveness of Teacher Education - A Theoretical Framework of Communicative Evaluation and the Design of a Finnish Research Project. In H. Niemi and K. Tirri (Eds.), Effectiveness of Teacher Education. New Challenges and Approaches to Evaluation Research series A 6/1996. Reports from the Department of Teacher Education in Tampere University (pp. 11-32). Tampere: University of Tampere.

Niemi, H. (2007). Life as Learning - the Finnish case of a national research programme, in T. Burns (Ed.), Research and Evidence in Educational PolicyMaking: new challenges, (pp. 117-123). Paris: OECD/CERI.

Niemi, H. (2014). Teachers as Active Contributors in Quality of Education: A Special Reference to the Finnish Context. In D. Hung, K. Y. T. Lim, \& S-S. Lee (Eds.), Adaptivity as a transformative disposition for learning in the 21st century (pp. 179199). Singapore: Springer

Niemi, H. (2016). The Societal Factors Contributing to Education and Schooling in Finland. In H. Niemi, A., Toom, \& A, Kallioniemi (Eds.), Miracle of Education: The 
Principles and Practices of Teaching and Learning in Finnish Schools (Second revised edition) (pp. 23-40). Rotterdam: Sense Publishers.

Niemi, H. \& Jakku-Sihvonen, R. (2006). Research-based teacher education. In R. Jakku-Sihvonen, R. \& Niemi, H. (Eds.), Research-based teacher education in Finland - reflections by Finnish teacher educators (pp. 31-50). Turku: Finnish Educational Research Association.

Niemi, H. \& Kemmis, S. (1999). Communicative Evaluation: Evaluation at the Crossroads', Lifelong Learning in Europe 1, 55-64.

Niemi, H. \& Kemmis, S. (2012). Communicative evaluation for improvement in education. In J. Harford, B. Hudson, \& H. Niemi (Eds.), Quality Assurance and Teacher Education: International Challenges and Expectations (pp. 53.82), Oxford: Peter Lang.

Niemi, H., Multisilta, J., Lipponen, L., \& Vivitsou, M. (Eds.) (2014). Finnish innovations \& technologies in schools: Towards new ecosystems of learning. Rotterdam: Sense Publishers.

Niemi, H., \& Nevgi. (2014). Research studies and active learning promoting professional competences in Finnish teacher education. Teaching and Teacher Education, 43, 131-142.

Niemi, H., Toom, A., \& Kallioniemi. A. (Eds.) (2016). Miracle of Education. The Principles and Practices of Teaching and Learning in Finnish Schools (Second revised edition). Rotterdam: Sense Publishers.

Nonaka, I., \& Toyama, R. (2003). The Knowledge-Creating Theory Revisited: knowledge creation as a synthesizing process. Knowledge Management Research \& Practice. 1, 2-10. http://dx.doi.org/10.1057/palgrave.kmrp.8500001

Robertson, S., \& Dale, R. (2007). Comments on the pre-final version of the draft papers of the three consultants (Leney, Niemi and Rickinson) on the links between research, policy and practice.” Nesse. Graduate School Education - University of Bristol.

Sahlberg, P. (2011). Finnish lessons: What can the world learn from educational change in Finland? New York: Teacher College Press.

Samuelson, P. A. (1954). The Pure Theory of Public Expenditure. The Review of Economics and Statistics, 36 (4), 387-389.

Scardamalia, M., \& Bereiter, C. (2003). Knowledge building. In Encyclopedia of education (2nd ed.) (pp. 1370-1373). New York: Macmillan Reference, USA.

Schuller, T. (2006). International policy research: 'evidence' from CERI/OECD, In J. Ozga, T. Seddon, T., \& T. Popkewitz (Eds.). Education Research and Policy. (pp. 78-90) .London: Routledge, 
Slavin, R. (2002). Evidence-based education policies: Transforming educational practice and research. Educational Researcher, 31 (7), 15-21.

UNESCO (2015). Rethinking Education: Towards a global common good? Paris: UNESCO.

Vahtivuori-Hänninen, S, Halinen, I., Niemi, H., Lavonen, J., \& Lipponen. L (2014). A new Finnish national core curriculum for basic education (2014) and technology as an integrated tool for learning. In H. Niemi, J. Multisilta, L. Lipponen, \& M. Vivitsou (Eds.), Finnish innovations \& technologies in schools: Towards new ecosystems of learning (pp. 21-32). Rotterdam: Sense Publishers.

Välijärvi, J. \& Sulkunen, S. (2016). Finnish school in international comparison. In H. Niemi, A. Toom, \& A, Kallioniemi (Eds.), Miracle of Education: The Principles and Practices of Teaching and Learning in Finnish Schools (Second revised edition) (pp. 3-23). Rotterdam: Sense Publishers.

Vitikka, E., Krokfors. L., \& Hurmerinta. E. (2016) The Finnish National Core Curriculum: Structure and Development. In H. Niemi, A. Toom, \& A, Kallioniemi (Eds.), Miracle of Education: The Principles and Practices of Teaching and Learning in Finnish Schools (Second revised edition) (pp. 83-90). Rotterdam: Sense Publishers. 